\title{
Aqueous humour turnover and intraocular pressure during menstruation
}

\author{
KEITH GREEN, '2* PATRICIA M. CULlEN,' AND CALBERT I. PHILliPS' \\ From the Department of 'Ophthalmology, University of Edinburgh and Princess Alexandra Eye Pavilion, \\ Royal Infirmary, Edinburgh; and the 2Departments of Ophthalmology and Physiology, \\ Medical College of Georgia, Augusta, Georgia, USA
}

SUMMARY Both intraocular pressure and aqueous humour turnover rate were determined at intervals over three months in three females in order to investigate whether a correlation existed between these variables and the menstrual cycle. Not only was there a lack of correlation between intraocular pressure or aqueous humour flow rate and menses but intraocular pressure and aqueous humour flow rate were also not related to each other. If pharmacologically administered doses of progesterone or oestrogen influence intraocular pressure, the present data indicate that the effect is probably mediated through effects on the aqueous outflow pathways.

The cyclical changes in oestrogens and progesterones during the menstrual cycle are well documented.' Despite several attempts, however, correlations between intraocular pressure (IOP), outflow facility $(\mathrm{C})$, and the menstrual cycle have not been definitely proved. ${ }^{2}$ An increased IOP has been reported to occur immediately before, or during menstruation. ${ }^{2.5}$ while an increased $\mathrm{C}$ during the progestational phase and a decreased $\mathrm{C}$ during the oestrogenic phase has also been reported. ${ }^{6}$ Paterson and Miller, ${ }^{7} 1$. . .cier, found a bicyclic increase in $C$ which occurred in both the mid-oestrogenic and the mid-oestrogenicprogesterone phases. An increased occurrence of glaucoma symptoms, especially in angle-closure versus open-angle glaucoma patients, has also been noted during the menses. ${ }^{5}$ Although pharmacological doses of progesterone $\mathrm{e}^{7-11}$ and oestrogen 112 have been shown to induce small decreases in IOP, it is not clear whether naturally produced progesterone plays a role in IOP regulation. ${ }^{13}$

We have measured IOP and aqueous humour turnover rate with fluorimetry at weekly intervals in three female volunteers through at least three consecutive menstrual cycles in order to determine whether correlations exist between these parameters and the menstrual cycle.

*On sabbatical leave from the Mcdical College of Gcorgia, 1982-3. Correspondence to Professor Keith Green, Department of Ophthalmology, Medical College of Gcorgia, MCG Box 3059, Augusta, GA 30912, USA.

\section{Materials and methods}

Three normal female volunteers, free from eye and systemic disease, aged 27,31 , and 35 , and not taking oral contraceptives, were recruited from the nursing and administrative staff of the Princess Alexandra Eye Pavilion. After signed, informed consent had been obtained a schedule was arranged to permit weekly determinations of fluorescein decay kinetics in the eye and IOP.

Each volunteer was given a calendar on which to mark the dates of menstruation and the date upon which they were tested. On the test day fluorescein eye drops (Fluress, Barnes-Hind, California) were either self administered or administered by a friend at a rate of one drop every two minutes between 0800 and $0830 \mathrm{~h}$. Readings were taken of corneal and mid anterior chamber fluorescein (over the pupil) every hour for 4 or 5 hours beginning at $1300 \mathrm{~h}$. Normal activities continued between readings. Fluorescein was detected by a Gamma scientific apparatus attached to a Haag-Streit 900 slit-lamp. ${ }^{14}$ Aqueous humour flow rate was determined according to the method of Jones and Maurice, ${ }^{15}$ using the linear decay of corneal and anterior chamber fluorescein after the peak concentrations had been reached. ${ }^{16}$ IOP was taken with a Goldmann tonometer immediately preceding the $1500 \mathrm{~h}$ reading. Determinations were made on as close to a weekly schedule as was possible. Unfortunately, over the last week of 
Table 1 Aqueous humour fluorescein decay kinetics for subject I

\begin{tabular}{|c|c|c|c|c|c|c|}
\hline Date & Eye & $\begin{array}{l}I O P \\
(\mathrm{mmHg})\end{array}$ & $\begin{array}{l}\text { Slope } \\
\text { (min I) }\end{array}$ & $\begin{array}{l}\text { Flow } \\
\left(\mu / \min ^{-1}\right)\end{array}$ & $\begin{array}{l}K_{m a} \\
(\min -1)\end{array}$ & Menses \\
\hline \multirow[t]{2}{*}{8 Nov 1982} & OD & 12 & $-(0 \cdot()() 21$ & $1 \cdot 00 \pm 0 \cdot 05$ & $(0 \cdot 0(0) 10$ & \\
\hline & OS & - & - & - & - & \\
\hline \multirow[t]{2}{*}{15 Nov 1982} & OD & 10 & $-(1) \cdot(x) 12$ & $(0 \cdot 56 \pm 0 \cdot() 2$ & $(0 \cdot()(0) 5$ & 18 Nov to \\
\hline & OS & 10 & $-0 \cdot(0) 48$ & $2 \cdot 57 \pm 0 \cdot 12$ & $(0 \cdot() 022$ & $23 \mathrm{Nov}$ \\
\hline \multirow[t]{2}{*}{22 Nov 1982} & OD & 10 & $-0.0(0) 38$ & $3.40 \pm(0 \cdot 30)$ & $0 \cdot(0) 16$ & \\
\hline & OS & 10 & -()$\cdot(x) 34$ & $2 \cdot 17 \pm() \cdot 12$ & $0 .(0015$ & \\
\hline \multirow[t]{2}{*}{ 3) Nov 1982} & OD & 14 & $-0) \cdot(x) 31$ & $1 \cdot 71 \pm 0 \cdot(04$ & $0 \cdot(0) 13$ & \\
\hline & OS & 12 & $-0) \cdot()(128$ & $1 \cdot 71 \pm 0.08$ & $(0 \cdot 0) 12$ & \\
\hline \multirow[t]{2}{*}{$6 \mathrm{Dcc} 1982$} & OD & 10 & $-(0 \cdot(0) 55$ & $2 \cdot(19 \pm 0 \cdot 14$ & ()$\cdot()(037$ & \\
\hline & OS & 10 & $-0 \cdot(0) 63$ & $3 \cdot(05 \pm 0 \cdot 18$ & $(0 \cdot() 031$ & \\
\hline \multirow[t]{2}{*}{14 Dec 1982} & OD & 11 & $-(0 \cdot() 031$ & $1 \cdot(09 \pm 0 \cdot(05$ & $0 \cdot(0) 17$ & 16 Dec to \\
\hline & OS & 10 & $-(0 \cdot()(0) 47$ & $3.67 \pm 0 \cdot 19$ & 0.0019 & $20 \mathrm{Dec}$ \\
\hline \multirow[t]{2}{*}{21 Dec 1982} & OD & 11 & -()$\cdot(0) 47$ & $1 \cdot 45 \pm(0 \cdot 17$ & $(0 \cdot() 026$ & \\
\hline & OS & 12 & -()$\cdot() 41$ & $1 \cdot 55 \pm 0 \cdot 17$ & 0.0019 & \\
\hline \multirow[t]{2}{*}{18 Jan 1983} & OD & 13 & -()$\cdot()() 38$ & $2 \cdot 31 \pm 0 \cdot() 6$ & $(0 \cdot() 016$ & 13 Jan to \\
\hline & OS & 10 & -()$\cdot(x) 45$ & $3 \cdot 7(0 \pm 0 \cdot 13$ & 0.0018 & 17 Jan \\
\hline \multirow[t]{2}{*}{25 Jan 1983} & OD & - & $-(0 \cdot() 051$ & $3 \cdot(16 \pm \pm 0 \cdot 22$ & $(0 \cdot()() 24$ & \\
\hline & OS & - & -()$\cdot()(0) 70$ & $3 \cdot 67 \pm 0 \cdot 50$ & $(0 \cdot 0) 36$ & \\
\hline \multirow[t]{2}{*}{1 Fcb 1983} & OD & 10 & $-0 \cdot 0053$ & $4 \cdot 52 \pm 0 \cdot 34$ & $(0 \cdot()(20)$ & \\
\hline & OS & 10 & -0.0063 & $4 \cdot 63 \pm 0 \cdot 30$ & $(0 \cdot()(1) 25$ & \\
\hline \multirow[t]{2}{*}{8 Feb 1983} & OD & 12 & $-0 \cdot(x) 34$ & $2 \cdot 22 \pm 0 \cdot 27$ & $(0 \cdot(0) 14$ & 10 Feb to \\
\hline & OS & 12 & $-(0 \cdot()() 11$ & $(0 \cdot 5() \pm 0 \cdot 10$ & $(0 \cdot 0)(0) 5$ & $14 \mathrm{Fch}$ \\
\hline
\end{tabular}

For explanation of slope, flow, and $K_{\text {iк:i }}$ sec text.

1982 and the first week of 1983 it was impossible to schedule sessions.

Data analysis was performed only after the completion of the four-month study during which measurements were made without knowledge of the times of the menstrual cycle of the volunteers. The slope is the rate of decay of fluorescein in the anterior chamber expressed as the natural log of fluorescein concentrations. It has the dimension of $\mathrm{min}^{-1}$, and was obtained by linear least squares methods. $\mathrm{K}_{\mathrm{aca}}$ is the transfer coefficient for fluorescein across the endothelium and has the dimension of $\min ^{-1}$. In order to calculate flow rate in $\mu 1 \mathrm{~min}^{-1}$ we assumed an anterior chamber value of $200 \mu \mathrm{l}$. Corneal volume was taken as $80 \mu \mathrm{l}$. While these values are slight overestimates of previously used values, ${ }^{16}{ }^{17}$ they do reflect recent estimates of anterior chamber and corneal volumes. ${ }^{1 \times 19}$

Table 2 Aqueous humour fluorescein decay kinetics for subject 2

\begin{tabular}{|c|c|c|c|c|c|c|}
\hline Date & Eye & $\begin{array}{l}I O P \\
(m m H g)\end{array}$ & $\begin{array}{l}\text { Slope } \\
\text { (min -1) }\end{array}$ & $\begin{array}{l}\text { Flow } \\
\left(\mu / \min ^{-1}\right)\end{array}$ & $\begin{array}{l}K_{\text {ua }} \\
(\min 1)\end{array}$ & Menses \\
\hline \multirow[t]{2}{*}{8 Nov 1982} & OD & 15 & $-0 \cdot()(048$ & $2 \cdot 49 \pm(0 \cdot 12$ & $0.0(023$ & \\
\hline & OS & 14 & $-0 \cdot() 056$ & $2.81 \pm 0.39$ & $0 \cdot(0) 34$ & \\
\hline \multirow[t]{2}{*}{16 Nov 1982} & OD & 16 & $-0 \cdot(x) 54$ & $2 \cdot 59 \pm(0 \cdot 17$ & $0 \cdot(0)(129$ & 14 Nov to \\
\hline & OS & 14 & $-0 \cdot(x) 23$ & $1 \cdot(08 \pm 0.03$ & $0 .(0) 11$ & $18 \mathrm{Nov}$ \\
\hline \multirow[t]{2}{*}{23 Nov 1982} & OD & 14 & $-0 \cdot(0) 56$ & $2 \cdot() 1 \pm 0 \cdot 14$ & $0 \cdot()(035$ & \\
\hline & OS & 13 & $-0 \cdot(0) 40$ & $1 \cdot 29 \pm(0 \cdot() 3$ & $0 \cdot(0) 30$ & \\
\hline \multirow[t]{2}{*}{$1 \mathrm{Dec} 1982$} & OD & 16 & $-0 \cdot(0) 43$ & $1 \cdot 46 \pm(0 \cdot 11$ & $0.0(129$ & \\
\hline & OS & 16 & $-(0 \cdot()(041$ & $1 \cdot 73 \pm 0 .(14$ & $0.0(1) 22$ & \\
\hline \multirow[t]{2}{*}{8 Dec 1982} & OD & 12 & $-0 \cdot(0070$ & $3 \cdot(05 \pm 0 \cdot 32$ & $0.0(045$ & 12 Dec to \\
\hline & OS & 12 & $-0 \cdot(0070$ & $3 \cdot 24 \pm(0.47$ & $0 .(0) 54$ & $15 \mathrm{Dec}$ \\
\hline \multirow[t]{2}{*}{22 Dec 1982} & OD & 14 & $-0 \cdot(x) 59$ & $2.90 \pm 0.59$ & $0.0(179$ & 7 Jan to \\
\hline & OS & 13 & $-0 \cdot(x) 43$ & $1 \cdot 76 \pm 0 \cdot 13$ & $0.0(1) 33$ & 11 Jan \\
\hline \multirow[t]{2}{*}{12 Jan 1983} & OD & 12 & -()$\cdot()(046$ & $1 \cdot 85 \pm 0.29$ & $0.0(19.5$ & \\
\hline & OS & 13 & $-(0 \cdot()(041$ & $1 \cdot 57 \pm 0 \cdot(09$ & $(0 \cdot()(029$ & \\
\hline \multirow[t]{2}{*}{19 Jan 1983} & OD & - & $-0.0(0) 38$ & $1 \cdot 36 \pm 0 \cdot(07$ & $0.0(027$ & \\
\hline & OS & - & $-0 \cdot(x) 46$ & $1 \cdot 85 \pm 0 \cdot 14$ & 0.0032 & \\
\hline \multirow[t]{2}{*}{8 Feb 1983} & OD & 14 & $-0 \cdot(x) 89$ & $3.73 \pm 0.73$ & 0.0076 & 2 Fch to \\
\hline & OS & 14 & $-0 \cdot(x) 47$ & $1 \cdot 10 \pm 0 \cdot 11$ & 0.0049 & 8 Fch \\
\hline
\end{tabular}

For explanation of slope, flow, and $K_{i k: i}$ sec text. 
Table 3 Aqueous humour fluorescein decay kinetics for subject 3

\begin{tabular}{|c|c|c|c|c|c|c|}
\hline Date & Eye & $\begin{array}{l}I O P \\
(m \operatorname{mH} H)\end{array}$ & $\begin{array}{l}\text { Slope } \\
\left(m_{i n}^{-1}\right)\end{array}$ & $\begin{array}{l}\text { Flow } \\
\left(\mu / \text { min }^{-1}\right)\end{array}$ & $\begin{array}{l}K_{u r a} \\
\left(\min ^{-1}\right)\end{array}$ & Menses \\
\hline \multirow[t]{2}{*}{15 Nov 1982} & OD & 14 & $-0 \cdot(0) 51$ & $2 \cdot(05 \pm 0 \cdot(07$ & 0.0029 & \\
\hline & OS & 14 & $-0 \cdot(0) 52$ & $2 \cdot 42 \pm(0 \cdot 19$ & 0.0026 & \\
\hline \multirow[t]{2}{*}{22 Nov 1982} & OD & 12 & $-0 \cdot()(024$ & $0 \cdot 67 \pm 0 \cdot() 2$ & $0 \cdot(0032$ & 21 Nov to \\
\hline & OS & 12 & $-0 .(0) 16$ & $0.51 \pm 0.01$ & $0 \cdot 0011$ & $25 \mathrm{Nov}$ \\
\hline \multirow[t]{2}{*}{ 30) Nov 1982} & OD & 15 & $-0 \cdot(0) 24$ & $0 \cdot 67 \pm 0 \cdot(04$ & 0.0017 & \\
\hline & OS & 10 & $-0 .(0) 22$ & $0.70 \pm 0.03$ & 0.0013 & \\
\hline \multirow[t]{2}{*}{6 Dec 1982} & OD & 14 & $-0 \cdot(0039$ & $1 \cdot 77 \pm 0.09$ & 0.0018 & \\
\hline & OS & 14 & $-0 \cdot(0) 31$ & $1 \cdot 56 \pm 0 \cdot 10$ & 0.0013 & \\
\hline \multirow{2}{*}{13 Dec 1982} & OD & - & $-0.0(0) 26$ & $1 \cdot 16 \pm 0 \cdot(04$ & $0 \cdot(0) 12$ & \\
\hline & OS & - & $-(0 \cdot 0) 25$ & $0.97 \pm 0.01$ & $0 .(0) 14$ & \\
\hline \multirow[t]{2}{*}{15 Dec 1982} & OD & 14 & -0.0063 & $2 \cdot 10 \pm 0 \cdot 07$ & 0.0051 & 20) Dec to \\
\hline & OS & 14 & $-0 \cdot(0) 61$ & $2 \cdot 58 \pm 0 \cdot 16$ & 0.0039 & $25 \mathrm{Dcc}$ \\
\hline \multirow[t]{2}{*}{22 Dec 1982} & OD & 14 & $-0 \cdot(0) 84$ & $2 \cdot 70 \pm 0 \cdot(06$ & $0.0(074$ & \\
\hline & OS & 14 & -0.0082 & $2 \cdot 65 \pm 0.50$ & 0.0050 & \\
\hline \multirow[t]{2}{*}{18 Jan 1983} & OD & 15 & $-0 \cdot(0) 31$ & $0 \cdot 84 \pm 0.05$ & 0.0030 & $18 \mathrm{Jan}$ to \\
\hline & OS & 15 & $-(0 \cdot()) 33$ & $0.98 \pm 0.07$ & $0 .(0) 22$ & $22 \mathrm{Jan}$ \\
\hline \multirow[t]{2}{*}{1 Fcb 1983} & OD & 11 & $-0.0(059$ & $3 \cdot 42 \pm 0.32$ & $0 \cdot 0021$ & \\
\hline & OS & 11 & $-0 \cdot(0) 39$ & $2 \cdot 96 \pm 0.61$ & 0.0014 & \\
\hline \multirow[t]{2}{*}{8 Fcb 1983} & OD & 13 & $-0 \cdot(0)(20)$ & $1 \cdot 01 \pm 0.13$ & 0.00008 & $17 \mathrm{Fcb}$ to \\
\hline & OS & 13 & $-0 \cdot(0) 76$ & $2 \cdot 82 \pm 0 \cdot 22$ & 0.0050 & $21 \mathrm{Fcb}$ \\
\hline
\end{tabular}

For explanation of slope, flow, and $\mathrm{K}_{\mathrm{ita}}$ sec text.

\section{Results}

The data obtained in this study are shown in Tables 1 to 3 . While variations exist in all parameters as a function of time, none of the variations appear to be correlated with any part of the menstrual cycle.

IOP variations for the subjects varied between 10 and $16 \mathrm{mmHg}$, and, although the values differed at various times of the cycle, they did not correlate with it over the course of several cycles. The mean IOP and aqueous humour flow rate values for both eyes of each subject are shown in Figs. 1 and 2 respectively.
These graphs illustrate the lack of correlation between these values and the occurrence of the menses.

Subject 1 tended to show a reduced IOP at or before the menstrual period for two of the four cycles, but her IOP was increased at other menses (Fig. 1). Subject 2 tended to have a slightly lower IOP after menses, although an exception occurred with the second menses in the testing series. No pattern existed for subject 3 , whose IOP could not be even vaguely correlated with menses (Fig. 1). Similarly, in Fig. 2 it is evident that no relationship exists between aqueous humour flow rate and the menstrual cycle.
Fig. 1 Plot of intraocular pressure versus time. Each set of symbols corresponds to the identification shown in the upper block where the menses are indicated for each subject.
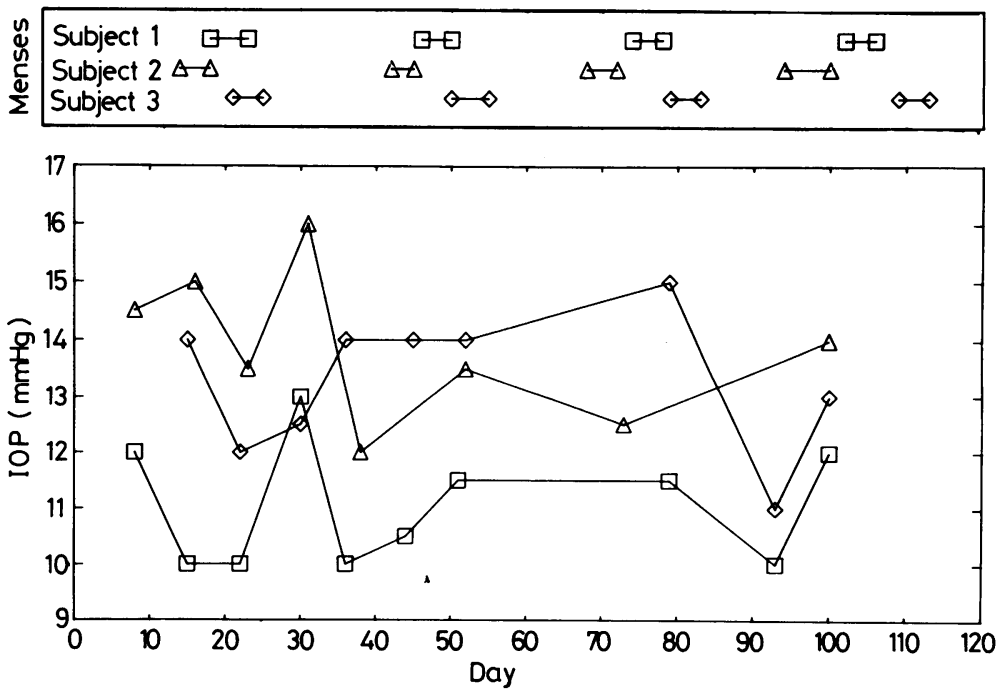

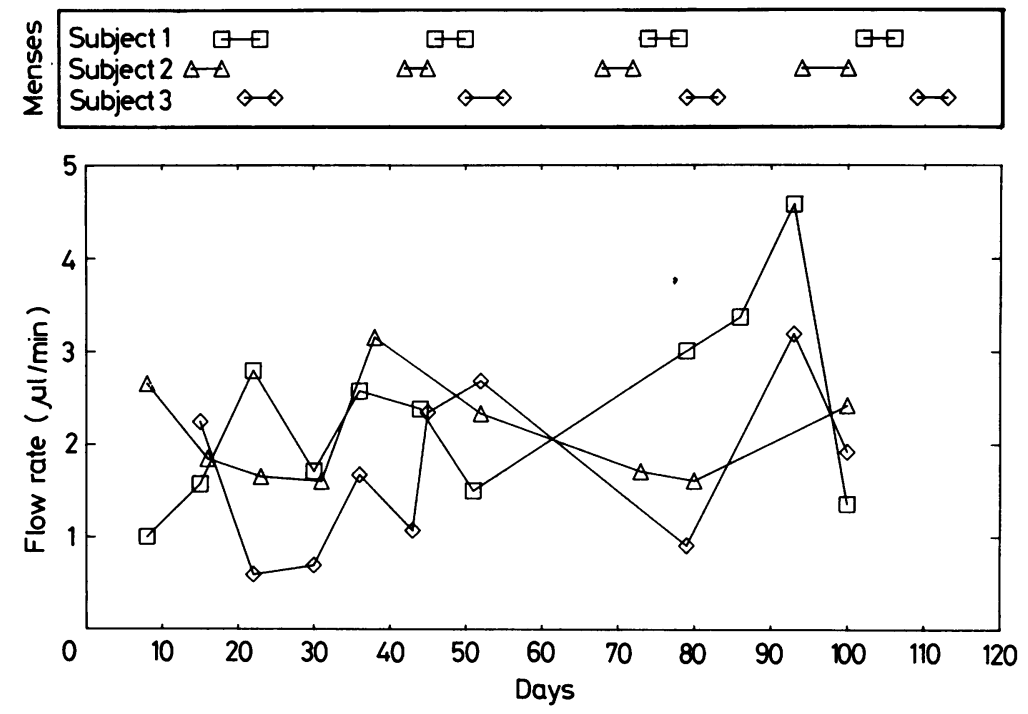

Fig. 2 Plot of aqueous humour flow (turnover) rate versus time. Each set of symbols corresponds to the identification shown in the upper block where the menses are indicated for each subject.
Comparison of Figs. 1 and 2 also illustrates that IOP can vary independently of aqueous humour flow rate.

\section{Discussion}

Fluorophotometry has proved valuable in assessing not only drug effects on aqueous humour dynamics $^{1620-22}$ but also in determining the changes in aqueous flow rate in a variety of clinical conditions. ${ }^{172-25}$ The validity of the technique has therefore been well proved. In the present study we assumed that the subjects had the same anterior chamber and corneal volumes, and, while this is probably not true, we were comparing changes which occurred with time in the same subjects, thus making the absolute value of the volumes of little importance. Nevertheless, the average values obtained for the slope, $K_{\text {aca }}$, and aqueous flow rate are very similar to those published in other studies. ${ }^{161721-25}$ Although the final number of subjects in the current study is small, the subjects were followed up for over three months, thus providing a longitudinal study of considerable duration, which is perhaps of more value than a shorter term study with more subjects. The subject drop-out rate was over $50 \%$ for several reasons.

Several studies have indicated an association between IOP or $\mathrm{C}$ and the menstrual cycle,$^{, 7}$ although a variety of changes have been noted in relation to the phases of the menstrual cycle. Certainly the administration of pharmacological doses of progesterones and oestrogens (alone or in combination) has been recorded to induce a small fall in intraocular pressure in both experimental animals ${ }^{26}$ and $\operatorname{man}^{7-1027}{ }^{2 x}$ despite some findings to the contrary. ${ }^{24-31}$

The present study indicates that the assumed normal, physiological hormonal changes associated with the menstrual cycle in our subjects had no influence on either IOP or aqueous flow, confirming at least one earlier study. ${ }^{2}$ If progesterone or oestrogen has an effect at pharmacological dose levels the mode of action cannot be deduced from our studies, though the lack of effect on aqueous inflow in our study would suggest that the steroid effect would be directed primarily towards the outflow pathways. Evidence exists that outflow facility is affected both in normal females and in those subjects treated with progesterone-oestrogens $^{6-x 12}$ as well as in experimental animals. ${ }^{32}$

We thank our voluntecrs (B.S., R.G., and L.T.) for gencrously giving their time to permit this study, Mrs Sylvia Catravas for her excellent secretarial assistance, and R. David Elijah for performing the fluorescein computations. The Gamma scientific fluorophotometer was purchased with funds made available by National Glaucoma Research, a programme of the Amcrican Health Assistance Foundation. Onc of us (KG) was supported in part by a Fogarty Senior International Fellowship, F06 TW00687, from the Fogarty Center, National Institutes of Health, Bethesda, Maryland.

We are grateful for the financial support of the W. H. Ross Foundation for the Study of the Prevention of Blindness.

\section{References}

1 Mountcastle VB. Medical physiology. Vol. 1. St. Louis: Mosby, 1968.

2 Feldman F, Bain J, Matuk AR. Daily assessment of ocular and hormonal variables throughout the menstrual cycle. Arch Ophthalmol 1978; 96: 1835-8.

3 Larsen V. Studien über dic Bezichungen des einfachen Glaukoma zur enneren Sckrction. Bibl Laeger 1934; 126: 318-22. 
4 Marx E. L’influence de la menstruation et de la grossesse sur la tension oculairc. Ann Oculist (Paris) 1923; 160: 873-82.

5 Dalton K. Influence of menstruation on glaucoma. Br J Ophthalmol 1967; 51: 692-5.

6 Becker B, Friedenwald JS. Clinical aqueous outflow. Arch Ophthalmol 1953; 50: 557-71.

7 Paterson GD, Miller SJH. Hormonal influence in simple glaucoma. BrJ Ophthalmol 1963; 47: 129-37.

8 Avasthi $P$, Luthra MC. Effect of sex hormones on intraocular pressure. Int Surg 1967; 48: 350-5.

9 Obal A. Gelbkorperhormon-Anwendung zur Glaukomtherapic. Klin Monatsbl Augenheilkd 1950; 117: 201-3.

10 Posthumus RG. The use and the possibilities of progesterone in the treatment of glaucoma. Ophthalmologica 1952; 124: 17-25.

11 Medgyaszar A. Intraocular pressure and hormonal therapy Ophthalmologica 1963; 145: 243-8.

12 Treister G, Mannor S. Intraocular pressure and outflow facility. Effect of estrogen and combined estrogen-progestin treatment in normal human eycs. Arch Ophthalmol 1970; 83: 311-8.

$13 \mathrm{Kass}^{\circ} \mathrm{MA}$, Sears ML. Hormonal regulation of intraocular pressure. Surv Ophthalmol 1977; 22: 153-76.

14 Waltman SR, Kaufman HE. A new objective slit lamp fluorophotometer. Invest Ophthalmol Visual Sci 1970; 9: 247-9.

15 Jones RF, Maurice DM. New methods of measuring the rate of aqueous flow in man with fluorescein. Exp Eye Res 1966; 5: $208-20$.

16 Yablonski ME, Zimmerman TJ, Waltman SR, Becker B. A fluorophotometric study of the effect of topical timolol on aqueous humor dynamics. Exp Eye Res 1978; 27: 135-42.

17 Nagataki S, Mishima S. Aqueous humor dynamics in glaucomato-cyclitic crisis. Invest Ophthalmol Visual Sci 1976; 15: 365-70.

18 Fontana ST, Brubaker RF. Volume and depth of the anterior chamber in the normal aging human eyc. Arch Ophthalmol 1980; 98: 1803-8.

19 Johnson SB, Coakes RL, Brubaker RF. A simple photogrammetric method of measuring anterior chamber volume. Am J Ophthalmol 1978; 18: 469-74.
20 Nagataki S, Brubaker RF. Effect of pilocarpine on aqueous humor formation in human beings. Arch Ophthalmol 1982; 100: 818-21.

21 Dailey RA, Brubaker RF, Bourne WM. The effects of timolol maleate and acetazolamide on the rate of aqueous formation in normal human subjects. Am J Ophthalmol 1982; 93: 232-7.

22 Nagataki S, Brubaker RF. Early effect of epinephrine on aqueous formation in the normal human cyc. Ophthalmology 1982; 88: 278-82.

23 Brubaker RF, Nagataki S, Townsend DJ, Burns RR, Higgins RG, Wentworth W. The effect of age on aqueous humor formation in man. Ophthalmology 1981; 88: 283-7.

24 Johnson DH, Brubaker RF. Dynamics of aqueous humor in the syndrome of exfoliation with glaucoma. Am J Ophthalmol 1982; 93: 629-34.

25 Wentworth WO, Brubaker RF. Aqueous humor dynamics in a series of patients with third neuron Horner's syndrome. Am J Ophthalmol 1981; 92: 407-15.

26 Lamble JS, Lamble AP. Some effects of progestrogens, oestrogens and androgens on the ocular tension of rabbits and owl monkeys. Exp Eye Res 1978; 26: 599-610.

27 Meyer EJ, Leibowitz H, Christman EH, Niffencgger JA. Influence of norethynodrel with mestranol on intraocular pressure in glaucoma. Arch Ophthalmol 1966; 75: 157-61.

28 Meyer EJ, Roberts CR, Leibowitz HM, McGowan B, Houle RE. Influence of norethynodrel with mestranol on intraocular pressure in glaucoma. II. A controlled double-blind study. Arch Ophthalmol 1966; 75: 771-3.

29 Lee PF, Donovan RH, Mukai N. Effect of norethynodrel with mestranol on the rabbit eye. Arch Ophthalmol 1969; 81: 89-98.

30 Siebenbiedel $\mathrm{H}$. The treatment of glaucoma with proluton. Disch Gesundh-Wes 1952: 7: 374-5.

31 Treumer K. The treatment of glaucoma with progesterone. Klin Monatsbl Augenheilkd 1952; 120: 523-34.

32 Gierek A, Sosnierz M, Bialas B, Szaflik J. Influence of estrogens on intraocular tension in the cyeballs of rabbits. Ophthalmology 1976; 172: 400-10. 